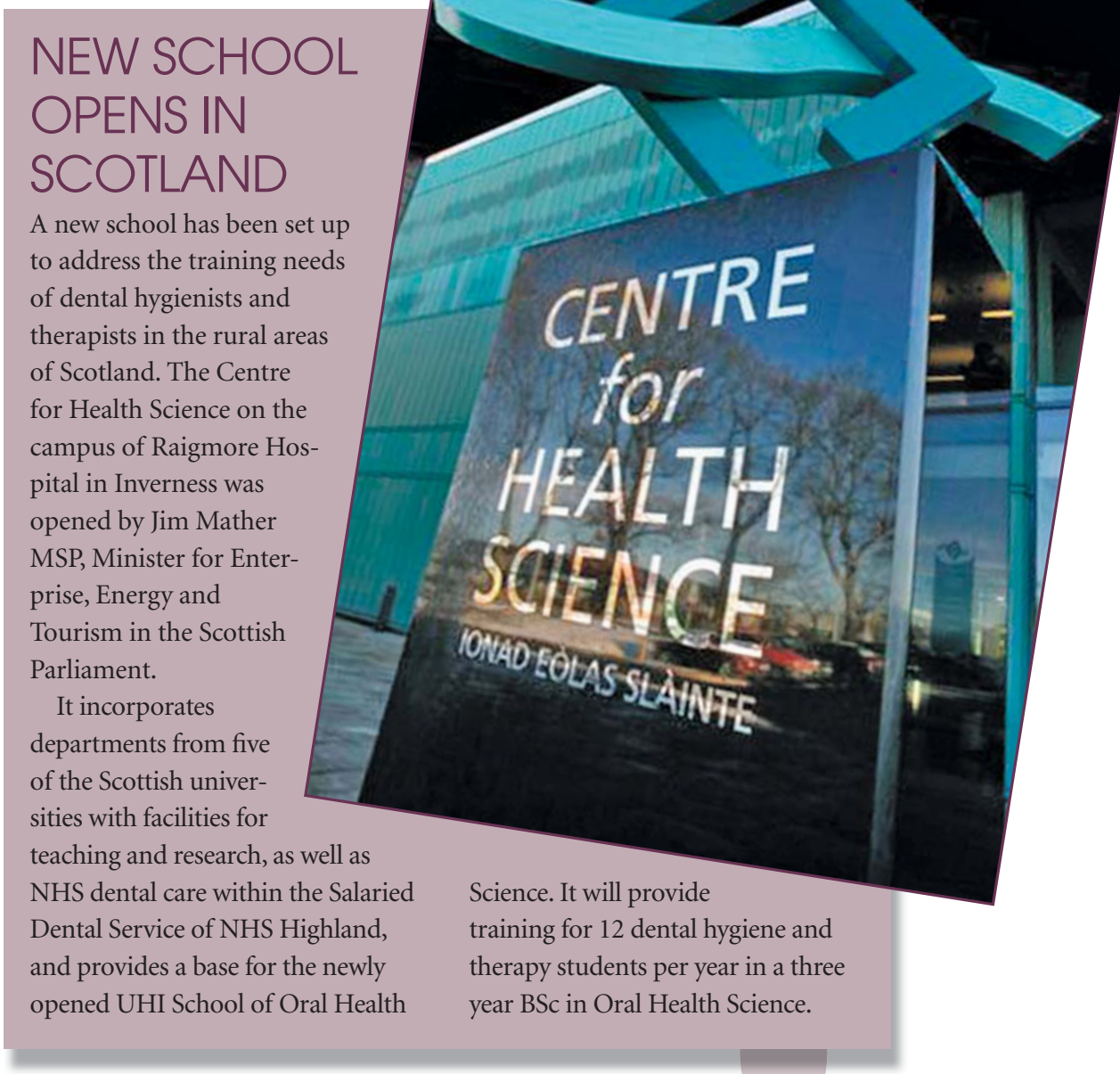

\section{NEW ONLINE OHE COURSE FOR DCPS}

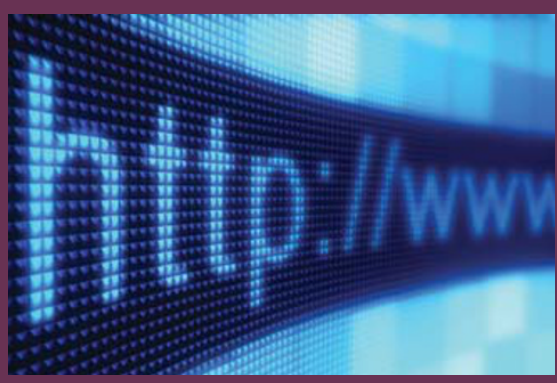

BDA Education has launched an online

course for dental care professionals who want to become Oral Health Educators. Following the same format as their extremely successful course in dental radiography, the new OHE course helps DCPs attain the NEBDN Certificate in Oral Health Education.

The course has been developed in partnership with OHE SW, a Bristol-based training company with many years' experience of teaching this subject. Students can learn how to instruct patients on oral hygiene with the innovative blend of online lectures, work-based exercises and support from our tutors.

To request an information pack and application form, call Elizabeth Clark on 02075636891 or visit www.bda.org.

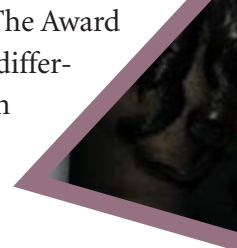

\section{SUCCESS AT BSDHT}

Marina Harris recently became President of the British Society of Dental Hygiene \& Therapy (BSDHT) at its Oral Health Conference \& Exhibition in Edinburgh. The event saw the launch of a competition to raise the profile of the profession among the general public.

The competition asked BSDHT members to design a leaflet that highlighted the range of skills offered by hygienists and therapists and exemplified the cosmetic, oral and general health benefits of regular visits.

The winner, Leigh Hunt, won a $£ 500$ cash prize and the winning entry will eventually be circulated to medical and non-medical organisations and to the public.

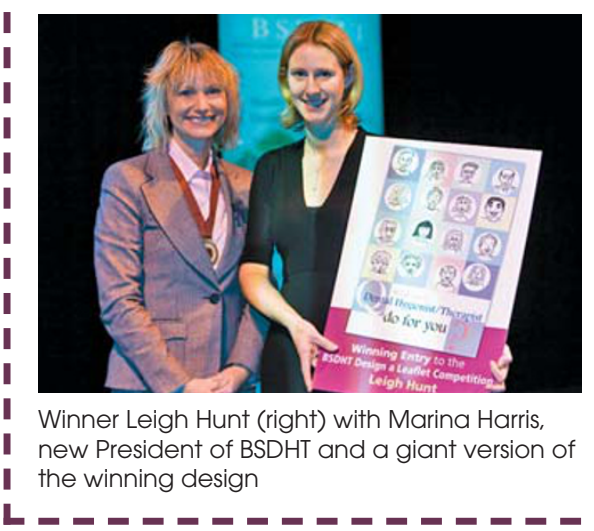

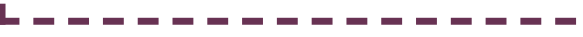

\section{COLLABORATION ANNOUNCED}

Proposals have been drawn up which will forge closer links between BOS and the Orthodontic National Group for Dental Nurses and Therapists $(\mathrm{ONG})$. The ONG will remain an affiliate of BOS retaining their own secretariat but will have a permanent address at the BOS office.

Organisation of its own journal and study days will continue as before and ONG members will be able to attend all BOS Conferences and many BOS meetings at reduced fees.

\section{AWARD WINNING MANAGER}

Kavita Verma of Sparkle Dental Boutique has won the prestigious 'Outstanding Individual of the Year' award at the 2008 Private Dentistry Awards. The Award underlines the difference one person can make to colleagues and patients.

Manager of the Sparkle Dental Boutique and BDA Good Practice Regional Consultant, Kavita was key in developing the Boutique into the award-winning practice it is today. 